Research Paper:

\title{
Spontaneous Intracranial Hypotension - Not Always Benign
}

\author{
Pavithran Vadakkam Muriyil ${ }^{1}$, Rajeev Mandaka Parambil ${ }^{1}$, , Shanavas Cholakkal $^{1} \mathrm{O}$, Akhil Mohan $^{1^{*}} \mathrm{O}$, Vishal Mangala $^{1} \mathrm{C}$
}

1. Department of Neurosurgery, Government Medical College, Kozhikode, Kerala, India

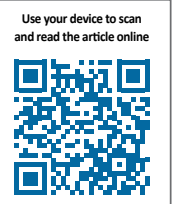

Citation: Vadakkam Muriyil P, Mandaka Parambil R, Cholakkal Sh, Mohan A, Mangala V. Spontaneous Intracranial Hypotension - Not Always Benign. Iran J Neurosurg. 2021; 7(2):85-91. http://dx.doi.org/10.32598/irjns.7.2.10

: http://dx.doi.org/10.32598/irjns.7.2.10

Article info:

Received: 12 Jan 2021

Accepted: 05 Mar 2021

Available Online: 01 Apr 2021

Keywords:

Spontaneous intracranial hypotension, Blood patch, Epidural, Orthostatic headache, Surgical repair

\section{ABSTRACT}

Background and Aim: Spontaneous Intracranial Hypotension (SIH) is a rare cause of headaches. It commonly presents with newly-developed persistent postural headaches and resolves with conservative treatment but rarely becomes a life-threatening disease. We retrospectively reviewed all cases of SIH patients treated in our institution for over ten years. Their clinical and radiological findings and the treatment given were analyzed. Their outcomes were assessed at a minimum of one year of follow-up.

Materials and Methods: We retrospectively reviewed all cases of SIH patients treated in our institution over ten years. Clinicoradiological aspects, as well as the treatment given, were analyzed. The outcome was assessed at a minimum of one year of follow-up.

Results: Six cases of SIH were studied. The Mean \pm SD age of the study population was $41.6 \pm 2.87$ years. Four cases (66\%) were female. The most common symptom was orthostatic headache which was present in all of them. The Mean \pm SD duration of symptoms before the diagnosis of SIH was $3 \pm 1.78$ months. Four cases were managed conservatively, while one patient was managed with surgery and the other with epidural patch repair. The exact site of the leak could be delineated in 2 cases (33\%). Two patients who were managed invasively for Cerebrospinal Fluid (CSF) the leak had a subdural hematoma. All patients had a favorable outcome at one year of follow-up.

Conclusion: Prompt and early identification of changes in symptom pattern and the onset of subdural hematoma are essential markers of shifting to definitive management rather than continuing conservative measures. Subdural hematoma, secondary to $\mathrm{SIH}$, warrants evacuation if it causes clinical deterioration.

\section{* Corresponding Author:}

Akhil Mohan, MD.

Address: Department of Neurosurgery, Government Medical College, Kozhikode, Kerala, India

Tel: +918 (714) 515685

E-mail:akhilmohan84@gmail.com 


\section{Highlights}

- The diagnostic and management dilemma in patients with SIH with subdural hematoma is discussed.

- Surgical repair of the CSF leak has its role, even though most SIHs can be managed with an epidural blood patch.

- Definitive management of the SIH should be sought once subdural hematoma has set in.

\section{Plain Language Summary}

There is a case series on the single institutional experience in diagnosing and managing spontaneous intra-cranial hypo-tension (SIH). SIH is an infrequent cause of headache, which worsens when the patient becomes upright. The management protocols are ill-defined, especially when the patient presents in a comatose state. There is always doubt in the mind of the treating physician when the patient has a subdural hematoma that is secondary to SIH. The enigmatic decision is whether to treat the hematoma first or to proceed with definitive management of the CSF leak that causes $\mathrm{SIH}$. Most cases of SIH can be managed conservatively. Early identification of the change in headache pattern or the development of subdural hematoma may be considered an indicator for changing from conservative measures to definitive invasive management. All patients managed in our series had a favorable outcome. This study highlights the importance of early clinical suspicion for diagnosing the condition (SIH) and results in a good product if prompt management is done. The article also has a literature review, especially on managing patients with SIH who present in a comatose state. Even though the mainstay in the definitive management of SIH is epidural blood patch, the surgical correction of CSF leak has its definite role in certain special situations, discussed in the article.

\section{Introduction}

pontaneous Intracranial Hypotension (SIH) is a rare cause of headache, which requires a high index of clinical suspicion for diagnosis. Because of the rarity of this condition, clinicians consider this as their last differential diagnosis. So, misdiagnosis of this condition varies from Arnold Chiari malformation to pituitary adenoma. SIH is caused by spontaneous spinal Cerebrospinal Fluid (CSF) leak, which is commonly seen in the cervicothoracic region. Even though the management of $\mathrm{SIH}$ is primarily conservative, epidural patch and surgical repair of the CSF leak have got their significance depending on the clinical status of the patient. So early identification of at-risk patients, while they are still on conservative management, is crucial for the overall prognosis. The most challenging aspect of management is to correctly identify the leak site before doing invasive management strategies like an epidural patch or surgical repair to seal the CSF leak directly.

\section{Methods and Materials/Patients}

We retrospectively reviewed the medical records and identified all patients diagnosed with SIH for ten years from January 2010 to December 2019 at Government Medical College, Kozhikode, Kerala, India. The patients were selected based on the International Classification of Headache Disorders (the $3^{\text {rd }}$ edition) guidelines [1, 2] (Table 1). Patients who had a prior lumbar puncture, head trauma, epidural anesthesia, or other causes of CSF leaks were excluded. Patients with persistent orthostatic headache and with supporting features of CSF leak in MR imaging were diagnosed as SIH. The supporting evidence on contrast-enhanced MRI brain includes subdural fluid collections, diffuse pachymeningeal enhancement, engorgement of venous structures, pituitary hyperemia, and sagging of the brain. The demographic details, clinical features, radiological imaging, and treatment given for the cases were studied. The outcomes were assessed with Glasgow Outcome Score (GOS) and Visual Analog Scale for pain (VAS) at a minimum follow-up of one year.

A 42-year-old man presented with daily persistent holocranial headache for six months, which was relieved on recumbency. MR imaging of the brain showed diffuse pachymeningeal enhancement with a prominence of dural sinuses and pituitary gland. There was decreased pontomammillary distance and flattening of ventral pons on clivus with sagging of brain (Figure 1). On clinicoradiologial examination, the diagnosis of $\mathrm{SIH}$ was made, and the patient was started on conservative management with bed rest, caffeine, deriphyllin, and fludrocortisone. On follow-up, the patient developed an exacerbation of headache, which persisted even in a ly- 
Table 1. International Classification of Headache Disorders $-3^{\text {rd }}$ Edition (ICHD-3) diagnostic criteria for intracranial hypotension headache [2]

\section{Diagnostic Criteria}

A. Any headache fulfilling criterion C

B. Either or both of the following:

1. Low Cerebrospinal Fluid (CSF) pressure $\left(<60 \mathrm{~mm} \mathrm{H}_{2} \mathrm{O}\right)$

2. Evidence of CSF leak on imaging

C. Headache has developed in temporal relation to the low CSF pressure or CSF leakage or led to its discovery

D. Not better accounted for by another ICHD-3 diagnosis

ing-down position. MR imaging of the brain was repeated, which showed bilateral SDH. MR myelogram was done, which showed CSF leak at C1C2 level on the right side (Figure 1). The patient was scheduled for an epidural blood patch, but on the next day, the GCS of the patient deteriorated, and he became comatose (E2M5V3) The outcomes were assessed with Glasgow Outcome Score (GOS) and Visual Analog Scale for pain (VAS) at a minimum follow-up of one year. His CT brain revealed enlargement of SDH with uncal herniation. The patient was taken for emergency burr-hole evacuation of the hematoma. After the procedure, the GCS improved (E3M6V4). But on the next day, the conscious level of the patient worsened. The epidural blood patch was abandoned, and the patient was taken for open surgical repair since the proven efficacy of the epidural blood patch varies around $30 \%-90 \%$ and may require multiple attempts. Right $\mathrm{C} 2$ hemilaminectomy was done, and the dural defect was identified at the right $\mathrm{C} 2$ nerve root exit area. The defect was sealed with crushed muscle and was reinforced with fibrin glue and gel foam. During the postoperative period, the patient showed consistent improvement and became fully conscious and alert by the third postoperative day. The patient is under followup for the last year, and he is symptom-free, and the postoperative follow-up imaging revealed reversion of all the preoperative MRI changes in the brain (Figure 1).

\section{Results}

Six cases of SIH were treated during the study period. The Mean \pm SD age of the study population was $41.6 \pm 2.87$ years. Four cases (66\%) were female. The most common symptom was orthostatic headache which was present in all of our cases. Other symptoms like tinnitus, nausea, and neck pain were present among $50 \%(n=3)$ of our subjects, and one patient had double vision. The Mean \pm SD duration of symptoms before the diagnosis of $\mathrm{SIH}$ was $3 \pm 1.78$ months. Four cases were managed conservatively, while one case was managed with surgery and epidural patch repair. The exact site of the leak could be delineated in one-third of our cases ( $n=2$ ) (Table 2). Two patients who were managed invasively for CSF leak had a Subdural Hematoma (SDH). The Mean \pm SD Visual Analog Score (VAS) for headache in our series before starting treatment was

Table 2. Initial working diagnosis, treatment given and outcome of diagnosed cases of spontaneous intracranial hypotension

\begin{tabular}{|c|c|c|c|c|c|c|c|c|}
\hline \multirow{2}{*}{ Cases } & \multirow{2}{*}{ Age (y) } & \multirow{2}{*}{ Gender } & \multirow{2}{*}{ Primary Diagnosis } & \multirow{2}{*}{ VAS $_{D}$} & \multirow{2}{*}{ Level of Leak } & \multirow{2}{*}{ Treatment } & \multicolumn{2}{|c|}{ Outcome } \\
\hline & & & & & & & GOS & VAS $_{F}$ \\
\hline 1 & 45 & Female & Migraine & 5 & - & Conservative & 5 & 3 \\
\hline 2 & 42 & Male & Migraine & 6 & $\mathrm{C} 1 \mathrm{C} 2$ & Surgery & 5 & 0 \\
\hline 3 & 38 & Female & Tension headache & 4 & - & Conservative & 5 & 2 \\
\hline 4 & 40 & Female & Migraine & 5 & - & Conservative & 5 & 3 \\
\hline 5 & 45 & Female & Migraine & 4 & - & Conservative & 5 & 2 \\
\hline 6 & 40 & Male & Migraine & 6 & T6T7 & Epidural Patch & 4 & 0 \\
\hline
\end{tabular}

GOS: Glasgow Outcome Score; VAS : Visual Analog Scale for Headache at Diagnosis; VAS: Visual Analog Scale for Headache at One Year Follow-up 


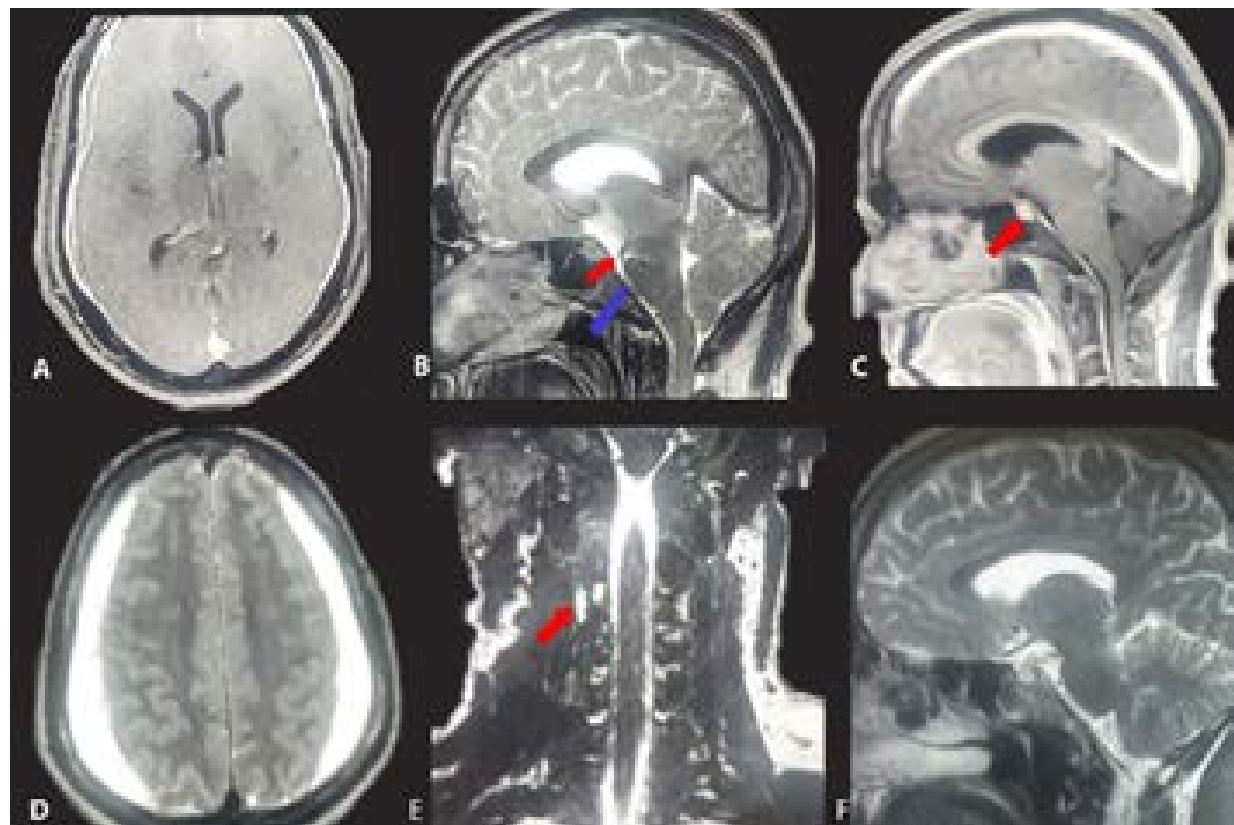

Figure 1. Serial MRI of the surgically treated patient

A: T1W axial sections of brain with diffuse pachymeningeal enhancement; B: T2W sagittal section showing flattening of ventral pons over civus (blue arrow) and decreased pontomammillary distance (red arrow); C: Gadolinium enhanced T1W sagittal images showing MRI sagittal showing sagging of brain structures with subdural correction of CSF and prominence of pituitary gland (red arrow); D: T2W axial MRI with bilateral subdural collection; E: T2W MR cisternogram with CSF leak at right C2 nerve root; F: T2W sagittal postoperative MRI at one month follow-up showing complete reversal of all the preoperative radiological changes.

$5 \pm 0.89$, which improved to $1.66 \pm 1.3$ at one year followup. About $83 \%$ of cases $(n=5)$ had a Glasgow Outcome Score (GOS) of 5 at one year follow-up and one patient had 4. All patients treated with invasive interventions in our series were completely symptom-free after one year.

\section{Discussion}

$\mathrm{SIH}$ is a relatively rare clinical condition with an incidence of 5 in 100000 per year [3]. This condition affects patients in the fourth and fifth decades of life with a preference for females [4]. This clinical condition can present with a multitude of symptoms, predominantly the orthostatic headache. These headaches are often present in the occipital region, which can worsen with the Valsalva maneuver. Mea et al., in their series of 70 patients, found that the prevalence of orthostatic headache is around 70\% [5]. Also, a headache that gradually progresses over the daytime, becoming severe during the afternoon hours called the 'second half headache' is expected.

The pathophysiology of SIH is better explained by CSF volume loss and lack of buoyancy to the brain than mere intracranial hypotension, resulting in sagging of the brain causing the symptoms and signs of this condition. This event also explains why intracranial CSF leaks are not causing the typical features of SIH. Spinal CSF leaks owing to the greater pressure gradient result in a considerable loss of CSF volume than what is lost in an intracranial CSF leak [1, 3]. The CSF leak is primarily due to meningeal diverticula $(42.3 \%)$ followed by a ventral or posterolateral dural tear (26.6\%) [6].

Reaching the diagnosis of SIH requires suspicion of the condition from the clinical history itself. Since this is a rarer cause of headache, no clinician will think of it as a primary diagnosis. This finding is evident from our series, in which none of our patients were diagnosed with $\mathrm{SIH}$ in the first instance (Table 2). Twenty percent of patients with SIH may have a normal MRI brain [7]. The diagnosis of SIH can be considered in a patient with an orthostatic headache if the imaging shows features of intracranial hypotension. But this becomes difficult when the patient presents primarily with subdural hematoma. A high index of clinical suspicion should be given when a patient presents with bilateral SDH of unknown cause since, in patients with $\mathrm{SIH}$, subdural bleedings are prevalent in $56 \%$ of cases [8]. More than $90 \%$ of cases of the SDH secondary to SIH are bilateral. Xia et al., in their study 
Table 3. Various series showing the incidence of SDH and Coma in patients with SIH

\begin{tabular}{|c|c|c|c|c|c|}
\hline \multirow{2}{*}{$\begin{array}{l}\text { Series/Year Published/Popula- } \\
\text { tion Size [Ref.] }\end{array}$} & \multicolumn{5}{|c|}{ No. (\%) } \\
\hline & $\begin{array}{c}\text { Number of } \\
\text { Cases With SDH }\end{array}$ & $\begin{array}{l}\text { Cases With } \\
\text { Coma }\end{array}$ & $\begin{array}{c}\text { Primary Evacua- } \\
\text { tion of SDH }\end{array}$ & $\begin{array}{l}\text { Definitive Manage- } \\
\text { ment of CSF Leak }\end{array}$ & Outcome \\
\hline Osada et al. /2019/4 [17] & $4(100)$ & $4(100)$ & $4(100)$ & $\begin{array}{l}\mathrm{EBP}-3(75) \\
\text { SRL- } 1(25)\end{array}$ & $\begin{array}{l}\text { Good-75 } \\
\text { Poor -25 }\end{array}$ \\
\hline Chen et al. /2014/227 [14] & $45(20)$ & $4(9)$ & $9(20)$ & $\begin{array}{c}\text { EBP- } 82 \\
\text { Conservative-18 }\end{array}$ & $\begin{array}{c}\text { Good-93 } \\
\text { Poor-7 }\end{array}$ \\
\hline Takahashi et al. /2016/169 [11] & $55(32.5)$ & $1(0.01)$ & $17(30.9)$ & $\begin{array}{c}\text { EBP- } 64.3 \\
\text { Conservative- } 36.7\end{array}$ & Good-100 \\
\hline Ferrante et al./2017/212 [12] & $35(16.5)$ & $8(22.8)$ & $2(5.7)$ & $\begin{array}{c}\text { EBP-95 } \\
\text { Conservative-5 }\end{array}$ & Good-100 \\
\hline Present Study/2021/6 & $2(33)$ & $2(33)$ & $2(100)$ & $\begin{array}{l}\text { EBP-1(50) } \\
\text { SRL-1(50) }\end{array}$ & Good-100 \\
\hline
\end{tabular}

of risk factors for the development of SDH in $\mathrm{SIH}$, found that duration of symptoms more than 30 days, venous distension sign on MRI, and diffuse pachymeningeal enhancement were independent risk factors [9].

Management of patients with subdural hematoma secondary to $\mathrm{SIH}$ is always a dilemma, especially when a patient has a clinical deterioration and presents in a comatose state. Whether to treat first the SDH or CSF leak has been a question of debate. We have two patients in this series who presented in the same fashion; both were managed with the evacuation of the SDH as an emergency measure since the clinical deterioration was thought to be due to the subdural bleeding. Postoperatively both patients had a transient improvement followed by clinical deterioration. Loya et al. reviewed the literature and studied patients with $\mathrm{SIH}$ who had clinical worsening to a comatose state. About $56 \%$ of these patients had an $\mathrm{SDH}$, among which $48 \%$ were treated primarily with the evacuation of the hematoma. Only half of the patients treated with primary surgery for SDH improved, at least transiently [10]. Various series have studied the incidence and management of SDH associated with $\mathrm{SIH}$, as well as the outcome of patients with deterioration in conscious levels (Table 3). Most of these studies show that the decision for primary evacuation of SDH is taken due to a decline in the patient's conscious state.

The irony of taking a clinical decision to evacuate the SDH becomes more intense since the SIH due to CSF leak can also lead to crowding of posterior fossa and cause brainstem dysfunction leading to a decline in the conscious level. In SIH, 34\% of patients can have cranial nerve palsies due to stretching of cranial nerves [10]. Pupillary dilatation, which is usually considered a sign of grave prognosis secondary to uncal herniation, can occur in SDH with mass effect. However, similar findings can also occur in SIH due to stretching the oculomotor nerves [10]. Various studies suggest that in treating a comatose patient with SDH secondary to $\mathrm{SIH}$, the patient should be kept in Trendelenburg position, which will help to relieve the pressure on the brainstem [8, 11-13]. While the proponents who are against the evacuation of SDH argue that the intracranial pressures recorded in various studies were subnormal. Once the cause of the CSF leak is fixed, most of these subdural bleedings usually resolve by themselves [14].

In our series, two patients had SDH secondary to SIH; both were treated initially with SDH evacuation. One patient whose leak was at the thoracic level was subsequently treated with an epidural blood patch, while the second patient who had the leak at the $\mathrm{C} 2$ nerve root dural sleeve was treated surgically. The fact that the patient deteriorated after the evacuation of $\mathrm{SDH}$, while post-evacuation imaging showing complete resolution of SDH with increased crowding of posterior fossa and no improvement with conservative measures like Trendelenburg position, hydration, etc. pushed us in favor of surgical repair of the leak rather than attempting an epidural blood patch. Also, the success rate of a single epidural blood patch in various series varies from $36 \%$ to $90 \%$. The sealing rate of the epidural blood patch is still lower in ventral and high cervical CSF leaks $[15,16]$.

In their retrospective study on patients with $\mathrm{SIH}$, Chen et al. stated that SDH more than $1 \mathrm{~cm}$ thickness was strongly associated with a chance of clinical deterioration. They also concluded in their study that refractory orthostatic headache or change in the pattern of headache can be taken as features of increased intracranial pressure, which should be addressed before treating the 
CSF leak [14]. On the contrary, Schievink et al. [18] studied eight patients with SDH and mass effect secondary to $\mathrm{SIH}$ and reported that all were managed effectively without evacuation of the hematoma and treating the CSF leak.

Development of SDH or worsening of symptoms in a patient managed conservatively can be considered as the failure of the conservative measures, and in such patients, the site of CSF leak should be identified, and definitive measures like epidural blood patch or surgical repair of the leak should be taken.

\section{Conclusion}

Even though most cases of SIH can be managed with conservative measures, constant follow-up is warranted. Prompt identification of changes in the pattern of headache or formation of SDH on follow-up imaging can be considered an indicator for quitting the conservative management and opting for definitive management to identify and seal the CSF leak either through epidural blood patch or by surgical repair. SDH with mass effect and deterioration in the sensorium may be managed with surgical evacuation but should be followed by definitive management of the CSF leak. Being a single institutional study with small study population, our results cannot be generalized.

\section{Ethical Considerations}

\section{Compliance with ethical guidelines}

Written informed consent was obtained from all patients/participants

\section{Funding}

This research did not receive any grant from funding agencies in the public, commercial, or non-profit sectors.

\section{Authors' contributions}

All authors equally contributed to preparing this article.

\section{Conflict of interest}

The authors declared no conflict of interest.

\section{References}

[1] Kranz PG, Malinzak MD, Amrhein TJ, Gray L. Update on the diagnosis and treatment of spontaneous intracranial hypotension. Current Pain and Headache Reports. 2017; 21(8):37. [DOI:10.1007/s11916-017-0639-3] [PMID]

[2] Arnold M. Headache classification committee of the International Headache Society (IHS) the international classification of headache disorders. Cephalalgia. 2018; 38(1):1-211. [DOI:10.1111/j.1468-2982.2008.01709.x] [PMID]

[3] Schievink WI. Spontaneous spinal cerebrospinal fluid leaks and intracranial hypotension. JAMA. 2006; 295(19):2286-96 [DOI:10.1001/jama.295.19.2286] [PMID]

[4] Wan Y, Xie J, Xie D, Xue Z, Wang Y, Yang S. Clinical characteristics of 15 cases of chronic subdural hematomas due to spontaneous intracranial hypotension with spinal cerebrospinal fluid leak. Acta Neurologica Belgica. 2016; 116(4):509-12. [DOI:10.1007/s13760-016-0597-2] [PMID]

[5] Kranz PG, Gray L, Amrhein TJ. Spontaneous intracranial hypotension: 10 myths and misperceptions. Headache. 2018;58(7):94859. [DOI:10.1111/head.13328] [PMID]

[6] Schievink WI, Maya MM, Jean-Pierre S, Nuño M, Prasad RS, Moser FG. A classification system of spontaneous spinal CSF leaks. Neurology. 2016; 87(7):673-9. [DOI:10.1212/ WNL.0000000000002986] [PMID]

[7] D'Antona L, Jaime Merchan MA, Vassiliou A, Watkins LD, Davagnanam I, Toma AK, et al. Clinical presentation, investigation findings, and treatment outcomes of spontaneous intracranial hypotension syndrome: A systematic review and metaanalysis. JAMA Neurology. 2021; 78(3):329-37. [DOI:10.1001/ jamaneurol.2020.4799] [PMID] [PMCID]

[8] Yoon SH, Chung YS, Yoon BW, Kim JE, Paek SH, Kim DG. Clinical experiences with spontaneous intracranial hypotension: A proposal of a diagnostic approach and treatment. Clinical Neurology and Neurosurgery. 2011; 113(5):373-9. [DOI:10.1016/j. clineuro.2010.12.015] [PMID]

[9] Xia P, Hu XY, Wang J, Hu BB, Xu QL, Zhou ZJ, et al. Risk factor for subdural haematoma in patients with spontaneous intracranial hypotension. PLoS One. 2015; 10(4):e0123616. [DOI:10.1371/ journal.pone.0123616] [PMID] [PMCID]

[10] Loya JJ, Mindea SA, Yu H, Venkatasubramanian C, Chang SD, Burns TC. Intracranial hypotension producing reversible coma A systematic review, including three new cases. Journal of Neurosurgery. 2012; 117(3):615-28. [DOI:10.3171/2012.4.JNS112030] [PMID]

[11] Takahashi K, Mima T, Akiba Y. Chronic subdural hematoma associated with spontaneous intracranial hypotension: Therapeutic strategies and outcomes of 55 cases. Neurologia MedicoChirurgica. 2016; 56(2):69-76. [DOI:10.2176/nmc.oa.2015-0032] [PMID] [PMCID]

[12] Ferrante E, Rubino F, Beretta F, Regna-Gladin C, Ferrante MM Treatment and outcome of subdural hematoma in patients with spontaneous intracranial hypotension: A report of 35 cases. Acta Neurologica Belgica. 2018; 118(1):61-70. [DOI:10.1007/s13760017-0845-0] [PMID]

[13] Davidson B, Nassiri F, Mansouri A, Badhiwala JH, Witiw CD, Shamji MF, et al. Spontaneous intracranial hypotension: A review and introduction of an algorithm for management. World Neurosurgery. 2017; 101:343-9. [DOI:10.1016/j.wneu.2017.01.123] [PMID] 
[14] Chen YC, Wang YF, Li JY, Chen SP, Lirng JF, Hseu SS, et al. Treatment and prognosis of subdural hematoma in patients with spontaneous intracranial hypotension. Cephalalgia. 2016; 36(3):225-31. [DOI:10.1177/0333102415585095] [PMID]

[15] Subramaniam V, Ganapathy S, Shivananda S, Nagabhushan KN, Murthy R. Recurrent spontaneous bilateral subdural hemorrhage as a consequence of high-cervical spontaneous CSF leak-lessons for neurosurgeons. Indian Journal of Neurosurgery. 2021; 10(1):6-12. https:// www.thieme-connect.com/products/ ejournals/abstract/10.1055/s-0040-1721203\#info

[16] Enomoto N, Mure H, Okazaki T, Azumi M, Okita S, Nagahiro S, et al. Posttraumatic cerebrospinal fluid leak associated with an upper cervical meningeal diverticulum. World Neurosurgery. 2018; 116:50-5. [DOI:10.1016/j.wneu.2018.05.061] [PMID]

[17] Osada Y, Shibahara I, Nakagawa A, Sakata H, Niizuma K, Saito R, et al. Unilateral chronic subdural hematoma due to spontaneous intracranial hypotension: A report of four cases. British Journal of Neurosurgery. 2020; 34(6):632-7. [DOI:10.1080/02688 697.2019.1667482

[18] Schievink WI, Maya MM, Moser FG, Tourje J. Spectrum of subdural fluid collections in spontaneous intracranial hypotension. Journal of Neurosurgery. 2005; 103(4):608-13. [DOI:10.3171/jns.2005.103.4.0608] 